\title{
A customized stylet for GlideScope® insertion of double lumen tubes
}

\author{
Jean S. Bussières, MD $\cdot$ Félix Martel, MD • \\ Jacques Somma, MD $\cdot$ Stéphane Morin, MSc • \\ Nathalie Gagné, PhD RRT
}

Received: 30 June 2011/Accepted: 16 January 2012/Published online: 1 February 2012

(C) Canadian Anesthesiologists' Society 2012

\section{To the Editor,}

The double lumen tube (DLT) is the airway of choice to establish and maintain lung isolation. However, it can be challenging to secure the airway with a DLT in patients with a difficult airway because DLTs are larger, more rigid, and more difficult to place into the trachea than single lumen tubes. Recently, a high level of success was achieved using the GlideScope ${ }^{\circledR}$ (GLS) to assist in positioning a single lumen tube (SLT) in situations where the airway was considered or proven to be difficult. ${ }^{1}$ The GLS has also been advanced for DLT placement in patients with difficult airways. ${ }^{2}$ In collaboration with Verathon Medical Canada ULC, we recently designed a new semi-rigid intubating stylet, the GlideRite DLT Stylet ${ }^{\circledR}$ (GR-DLT-S) (Figure), which can be used for primary DLT intubation with the GLS. The GlideRite DLT Stylet ${ }^{\circledR}$ (Verathon Medical Canada ULC, Burnaby, BC, Canada) is a reusable device which has been commercially available since March 2010 (In Canada, information on the device is available from CAREstream Medical Ltd., Langley, BC, Canada).

We undertook a preliminary study to observe the efficiency of the GR-DLT-S for primary insertion of a DLT with the GLS in patients presenting a normal upper airway. After obtaining Research Ethics Board approval from our institution, 50 adult patients scheduled for thoracic surgery and requiring lung isolation were enrolled after written informed consent. Exclusion criteria included patients with anticipated difficult bag-mask ventilation of the lungs or

J. S. Bussières, MD (ه) · F. Martel, MD · J. Somma, MD .

S. Morin, MSc · N. Gagné, PhD RRT

Institut Universitaire de Cardiologie et de Pneumologie de

Québec, Quebec City, QC, Canada

e-mail: jean.bussieres@anr.ulaval.ca anticipated difficult tracheal intubation according to the standard criteria, ${ }^{2}$ such as Mallampati class $>3$.

Following application of routine monitors, pre-oxygenation, induction, and paralysis, tracheal intubation with the DLT was undertaken using both the GLS and the GR-DLT-S. Forty-nine (98\%) patients received tracheal intubation using the combination of DLT/GLS/GR-DLT-S. The mean time required for intubation was 46.3 (32.3) sec. The number of attempts was one in 37 patients (74\%), two in 11 patients (22\%), and three in one patient (2\%). None of the subjects experienced complications associated with DLT insertion.

Three publications have described the use of the Glidescope ${ }^{\circledR}$ to facilitate DLT tracheal intubation. In 2005, Hernandez et al. described the first use of the GLS to introduce a DLT. ${ }^{3}$ In 2008, Chen et al. described a failure to insert a DLT with the GLS. They used the GLS to introduce a SLT, and afterwards, they used a tube exchanger to replace the SLT with a DLT, also with the assistance of the GLS. ${ }^{4}$ Finally, Bustamante et al. described a case report where bending the malleable stylet and sequential rotation of the DLT enabled them to introduce the DLT successfully. These authors reported a dozen successful cases using this technique. ${ }^{5}$ Over the past five years, we had several cases where we failed to intubate the trachea with a DLT using a similar method. The failed cases involved patients with little room to maneuver the DLT due to a large tongue or a small mouth opening. In these cases, the malleable stylet was not sufficiently rigid to maintain the optimal tube curvature. Since the introduction of the GR-DLT-S, tracheal intubation with the DLT has been successful using this new device in more than 15 patients with either a proven or an anticipated difficult airway.

In conclusion, based on our initial experience, we suggest that the GR-DLT-S is effective when used in 


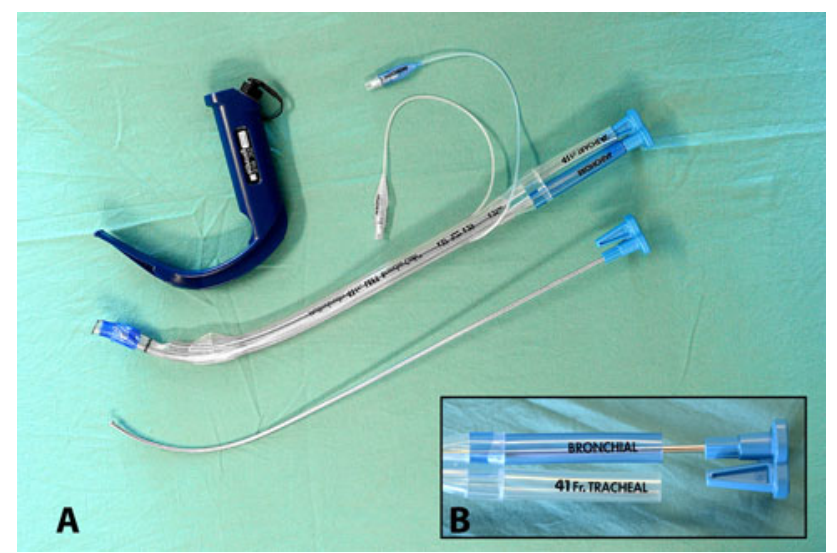

Figure A) Upper left panel: GlideScope ${ }^{\circledR}$; Center: GlideRite Double Lumen Tube Stylet ${ }^{\circledR}$ inserted in a 41Fr left double lumen tube; Lower right: GlideRite Double Lumen Tube Stylet ${ }^{\circledR}$; B) Adequate insertion of the handle of the GlideRite Double Lumen Tube Stylet ${ }^{\circledR}$ in a double lumen tube

combination with the GLS to insert a DLT in patients with a normal upper airway and also in patients with small and anticipated difficult upper airways. An option to consider is the use of the semi-rigid stylet (GR-DLT-S) especially designed to establish and maintain the optimal curvature of the DLT when combined with the GLS.
Financial support Intramural departmental sources.

Competing interest In collaboration with Verathon Medical Canada ULC, the authors designed a new semi-rigid intubating stylet, the GlideRite DLT Stylet ${ }^{\circledR}$ (GR-DLT-S), which can be used for primary DLT intubation with the GLS.

\section{References}

1. Aziz MF, Healy D, Kheterpal S, Fu RF, Dillman D, Brambrink $A M$. Routine clinical practice effectiveness of the Glidescope in difficult airway management: an analysis of 2,004 Glidescope intubations, complications, and failures from two institutions. Anesthesiology 2011; 114: 34-41.

2. Campos $J H$. Lung isolation techniques for patients with difficult airway. Curr Opin Anaesthesiol 2010; 23: 12-7.

3. Hernandez AA, Wong DH. Using a Glidescope for intubation with a double lumen endotracheal tube. Can J Anesth 2005; 52: 658-9.

4. Chen A, Lai HY, Lin PC, Chen TY, Shyr MH. GlideScope-assisted double-lumen endobronchial tube placement in a patient with an unanticipated difficult airway. J Cardiothorac Vasc Anesth 2008; 22: $170-2$.

5. Bustamante S, Parra-Sanchez I, Apostolakis J. Sequential rotation to insert a left double-lumen endotracheal tube using the GlideScope. Can J Anesth 2010; 57: 282-3. 